\begin{tabular}{|c|c|c|c|}
\hline $\begin{array}{c}\text { Case Reports in } \\
\text { ind }\end{array}$ & \begin{tabular}{|l} 
Case Rep Neurol 2011;3:54-61 \\
DOI: $10.1159 / 000324927$
\end{tabular} & $\begin{array}{l}\text { Published online: } \\
\text { February 21, } 2011\end{array}$ & $\begin{array}{l}\text { () } 2011 \text { S. Karger AG, Basel } \\
\text { ISSN } 1662-680 X \\
\text { www.karger.com/crn }\end{array}$ \\
\hline
\end{tabular}

\title{
Cerebellar Degeneration as Presenting Symptom of Recurrent Endometrial Stromal Sarcoma with Sex-Cord Elements
}

\author{
Michael Gliem ${ }^{\mathrm{a}} \quad$ Dimitris Panayotopoulos $^{\mathrm{b}}$ Peter Feindt ${ }^{\mathrm{c}}$ \\ Sebastian Heikaus $^{d}$ Markus C. Fleisch ${ }^{b}$ Rüdiger J. Seitz ${ }^{a}$ \\ Departments of a Neurology, ${ }^{b}$ Obstetrics and Gynecology, ${ }^{c}$ Cardiovascular Surgery

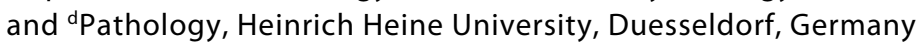

\section{Key Words}

Endometrial stromal sarcoma $\cdot$ Paraneoplastic syndrome · Sex-cord elements · Cerebellar atrophy - Ataxia

\begin{abstract}
We report a 66-year-old woman with slowly progressive ataxia due to cerebellar atrophy. Imaging studies revealed multiple lesions in both the lungs and dorsal subpleural space.

A biopsy identified the lesions as metastases of a low-grade endometrial stromal sarcoma containing sex-cord elements. The histological appearance was identical to a uterine tumor the patient was treated for with hysterectomy 16 years before. The metastases were removed surgically, and after 3 months ataxia had regressed. We conclude that the presenting cerebellar degeneration in this patient resulted from the metastatic recurrence of the endometrial tumor.
\end{abstract}

\section{Introduction}

Paraneoplastic syndromes (PS) represent a heterogeneous group of disorders that reflect the remote effects of cancer arising in any specific organ system. Some PS affect the nervous system and may precede the detection of the actual cancer by months or even years [1]; they can also be indicative for the specific site of the primary cancer. Subacute cerebellar degeneration of paraneoplastic origin occurs in approximately two thirds of female patients aged $\geq 50$ years [2]. Paraneoplastic cerebellar atrophy (PCA) is a rare syndrome that is mainly observed in patients with gynecologic cancers and is characterized by widespread loss of Purkinje cells [3]. Clinically, patients may present 
with predominant or isolated gait ataxia and evidence of truncal and hemispheric cerebellar dysfunctions such as diplopia, vertigo, lack of coordination, dysarthria and nystagmus [1]. PCA can precede or follow the diagnosis of cancer and has been described in patients with malignancies of the breast, ovary, endometrium or fallopian tube $[1,3]$. Purkinje cell degeneration is associated with circulating anti-Purkinje cell antibodies (anti-Yo). Interestingly, in gynecologic cancer patients with cerebellar degeneration, tumor cells express the corresponding Purkinje cell antigens [3]. Here, we report a case of a patient in whom cerebellar ataxia led to the diagnosis of a multifocal recurrent lowgrade endometrial stromal sarcoma (ESS) with sex-cord elements following a disease-free period of 16 years. We describe biological and clinical characteristics of ESS and discuss current treatment options.

\section{Case Report}

A 66-year-old patient was referred to our neurology department with a 3-year history of slowly progressing gait ataxia, truncal imbalance, blurred vision due to saccadic eye movements, horizontal and vertical gaze-evoked nystagmus (fig. 1 a, b), and slight dysarthria. Neurological examination disclosed no additional abnormalities. Sixteen years prior to this admission, the patient underwent an abdominal hysterectomy with bilateral salpingo-oophorectomy (BSO) for a symptomatic fibroid uterus. Unexpectedly, histology revealed a low-grade ESS with sex-cord elements. There was no residual disease, and the patient received no adjuvant therapy. Postoperative follow-up and annual screening exams were uneventful, and the patient took estrogen-based hormone replacement therapy (HRT).

On admission, an MRI scan of the brain showed a cerebellar atrophy mainly involving the upper vermis (fig. $2 \mathrm{a}, \mathrm{b}$ ). On CT scans of the chest and abdomen, bilateral pulmonary and subpleural metastases infiltrating the eighth and ninth thoracic vertebrae were observed (fig. $2 c, d$ ). There was no evidence of a local recurrence. The cerebrospinal fluid contained 2 leukocytes/ $\mu$, was negative for malignant cells and oligoclonal bands, and showed a normal protein content and a normal IgG index of 0.4. Investigations on vitamin $\mathrm{E}$, neurotropic viruses and bacterial agents were negative. In order to determine the tumor entity leading to the pulmonary and bone metastases, a CT-guided biopsy of the pulmonary lesions was performed, showing that the lesions were metastases of the formerly diagnosed low-grade ESS, again containing sex-cord elements (igg. 3). Cells were expressing CD10, had a low mitotic rate with 6 mitoses/10 HPF, and $80 \%$ were expressing estrogen receptor and $10 \%$ progesterone receptor. Screening for the antineuronal antibodies anti-Hu, anti-Ri, anti-Yo, anti-CV2, anti-Antiphysin and anti-Ma2 in the patient's serum by IgG immunoblotting showed no significant result. Nevertheless, due to the patient's cerebellar dysfunction combined with the cerebellar atrophy, we performed an additional immunohistochemical staining which also disclosed no affinity of the patient's serum to paraffin sections of human cerebellum, excluding the presence of anti-Hu and anti-Yo cerebellar antibodies.

Owing to the clinically suspected paraneoplastic origin of the cerebellar atrophy, the slight progression of the metastases within 4 months as evident on a follow-up CT scan of the lungs, and the unlikely response to chemotherapy due to a low proliferation index, the decision of the interdisciplinary tumor board was to perform surgical debulking in order to remove all evident sites of tumor recurrence. In a first operation, a left inferior lobectomy and a mediastinal node dissection were performed, removing 3 metastases up to $6 \mathrm{~cm}$ in diameter and 44 negative lymph nodes. Synchronously, a subpleural metastasis infiltrating the eighth and ninth thoracic vertebrae was removed, with residual macroscopic disease requiring postoperative focal radiation therapy. Four weeks later, after an uneventful postoperative course, 3 wedge resections of the right superior, middle and inferior lobe as well as a lymph node dissection were performed, removing 7 metastases up to $3 \mathrm{~cm}$ in diameter and 5 negative lymph nodes. The patient was discharged at day 10. In the first follow-up visit after the radiotherapy, she complained of shortness of breath in consequence of the reduced total lung volume. She was counselled to quit her HRT and was prescribed anastrozole as adjuvant therapy with the intention to delay further recurrence. After 3 months of follow-up, she is now without evidence of tumor. On repeated neurological examination, there was a virtually complete resolution of ataxia, but the oculomotor abnormalities persisted (fig. 1c). 


\begin{tabular}{l|l|l|l} 
Casp Reports in & $\begin{array}{l}\text { Case Rep Neurol 2011;3:54-61 } \\
\text { DOI: 10.1159/000324927 }\end{array}$ & $\begin{array}{l}\text { Published online: } \\
\text { February 21, 2011 }\end{array}$ & $\begin{array}{l}\text { ○ 2011 S. Karger AG, Basel } \\
\text { ISSN 1662-680X } \\
\text { www.karger.com/crn }\end{array}$ \\
\hline
\end{tabular}

\section{Discussion}

Our patient presented with clinical signs of slowly progressing ataxia which prompted us to a broad search, including for a neoplastic cause. In fact, we found prominent thoracic metastases of an ESS which had been treated with hysterectomy 16 years earlier. In accordance with a PS [4], the patient's symptoms regressed after tumor extirpation. ESS together with benign endometrial stromal nodules represent a subgroup of endometrial stromal tumors derived from uterine mesenchymal tissue (WHO classification 2003) and are composed of cells resembling the endometrial stroma in its proliferative phase. They are rare, accounting for only 6-20\% of all uterine sarcomas and $0.2 \%$ of all uterine malignancies. ESS were formerly divided into high- and low-grade ESS. Tumors previously termed high-grade ESS are now called poorly differentiated or undifferentiated uterine sarcomas, whereas low-grade tumors are still labelled ESS according to the current definition [5]. ESS show infiltrating borders and have a potential for recurrence and metastasis [6]. Recently, the International Federation of Gynecology and Obstetrics (FIGO) introduced a new classification and staging system in which leiomyosarcomas and ESS, due to their similar biology, are classified in 1 staging group (FIGO 2009). Both ESS and ESN may contain so-called sex-cord elements, first reported by Clement and Scully [7], and have been divided into 2 groups: ESS with sex cord-like elements (ESTSCLE) and uterine tumors resembling ovarian sex-cord tumors (UTROSCT) [8]. For UTROSCT, sex-cord differentiation is dominant or complete $(>50 \%)$. ESTSCLE contain focal sex cord-like areas in a background of an otherwise typical endometrial stromal nodule or ESS. They show an earlier tumor spread, have higher recurrence rates and a worse prognosis compared to UTROSCT [8]. Both can be considered as polyphenotypic neoplasias most likely derived from pluripotent mesenchymal progenitor cells. Accordingly, the tumor of the patient in this report can be classified as ESTSCLE.

Patients with ESS are mostly diagnosed between the age of 40 and 60 years. They may present with vaginal bleeding, abdominal pain, or an enlarged uterus which can be misinterpreted as a fibroid uterus. Both ultrasonography and MRI are sensitive but not specific to detect lesions. Since the endometrium is also involved in most cases, curettage can lead to the correct diagnosis. However, as in our patient, diagnosis is mostly incidentally made after hysterectomy.

ESS show an indolent growth and recur even at early stages in $36-56 \%$ of cases $[6,9]$. Recurrences have been reported from 3 months to 23 years after the initial diagnosis, but the median time to recurrence ranges between 65 (stage 1) and 9 months (stages 3 and 4), respectively, so that long-term follow-up is mandatory. ESS show a considerably benign biology as indicated by 5 -year survival rates of $62-93 \%$, depending on stage and differentiation [10]. Sites of recurrence are mainly the pelvis or other intraperitoneal locations, but distant metastases, as in our case, are frequently located in the lungs [6].

\section{Therapy}

Due to the rarity of these tumors, information is only available from case reports; general treatment recommendations or guidelines based on prospective studies do not exist. Recently, Amant et al. [5] have given a comprehensive overview of current treatment options. A preoperative noninvasive staging using CT or MR imaging can 


\begin{tabular}{l|l|l|l} 
Case Reports in & $\begin{array}{l}\text { Case Rep Neurol 2011;3:54-61 } \\
\text { DOI: } 10.1159 / 000324927\end{array}$ & $\begin{array}{l}\text { Published online: } \\
\text { February 21, 2011 }\end{array}$ & $\begin{array}{l}\text { ○ 2011 S. Karger AG, Basel } \\
\text { ISSN 1662-680X } \\
\text { www.karger.com/crn }\end{array}$ \\
\hline
\end{tabular}

detect metastatic spread and is mandatory for correct staging. Total hysterectomy in combination with BSO and careful abdominal exploration is commonly accepted as treatment of choice for early-stage cases confined to the uterus (stage I-II) [5]. Since most ESS express hormone receptors, BSO appears to be a logical treatment for a hormonesensitive tumor. However, its actual benefit has not been demonstrated, as some studies [11] could not find a survival difference in women with ESS treated with or without BSO, so that especially in young women with small tumors some authors recommend an individualized approach [5]. Although lymph node involvement can already be found at early stages in approximately 6-9\% of patients, a routine systematic pelvic and periaortic lymph node dissection does not appear to provide a survival benefit; thus, only suspicious or enlarged nodes should be removed under the aspect of cytoreduction [11, 12].

Retrospectively, the patient presented in our report underwent standard initial surgery including total hysterectomy and BSO. Considering the generally benign course of the disease, in cases of recurrence repeated surgeries aiming to remove all manifestations are also a viable treatment option.

As ESS expresses both estrogen and progesterone receptors, some authors suggested that adjuvant-targeted hormonal treatment with either progestins [e.g. medroxyprogesterone $(250 \mathrm{mg} / \mathrm{d})$ or megestrol $(160 \mathrm{mg} / \mathrm{d})]$ or aromatase inhibitors can reduce recurrence rates $[12,13]$. Sequential administration of progestins (megestrol acetate) followed by an aromatase inhibitor (letrozole or anastrozole) has also been reported to stabilize or improve the course of the disease. However, there exist no prospective studies investigating adjuvant hormonal treatment for ESS; additionally, there is no consensus regarding the treatment duration or the potentially additional effect of BSO [14].

Our patient did not receive any adjuvant therapy after the initial surgery. In fact, she continued her HRT. Chu et al. [13] speculate in their small case series that estrogen replacement after the diagnosis of ESS might be associated with a poor outcome. Chemotherapy should be reserved for hormone receptor-negative cases, cases with progression or recurrence under progestin or aromatase inhibitor therapy, or those cases progressing into a high-grade malignancy. Different regimens have been reported to be effective. Combined adjuvant chemotherapy with cisplatin and adriamycin has been shown to improve the survival rate in high-risk patients. In a previous GOG study, also ifosfamide ( $1.5 \mathrm{~g} / \mathrm{m}^{2}$ on days $1-5$ every 3 weeks) was effective in the therapy of women with chemotherapy-naïve, metastatic or recurrent ESS, with an overall response rate of $33.3 \%$. Additionally, combinatory chemotherapies containing ifosfamide $2 \mathrm{~g} / \mathrm{m}^{2}$, epirubicin $40 \mathrm{mg} / \mathrm{m}^{2}$ and cisplatin $60 \mathrm{mg} / \mathrm{m}^{2}$, or doxorubicin $50 \mathrm{mg} / \mathrm{m}^{2}$ and ifosfamide $5 \mathrm{~g} / \mathrm{m}^{2} / 24 \mathrm{~h}$ every 3 weeks were shown to lead to a clinical response in metastatic disease.

\section{Conclusion}

PS of the nervous system may accompany malignant tumors and require early identification and effective treatment of the underlying neoplasm [15]. Cerebellar degeneration and its concomitant symptoms have been associated with various gynecologic malignancies and therefore require increased awareness of both neurologists and gynecologists. We showed that PCA can also occur in combination with late recurrent ESS. 


\section{Disclosure Statement}

The authors have nothing to disclose.

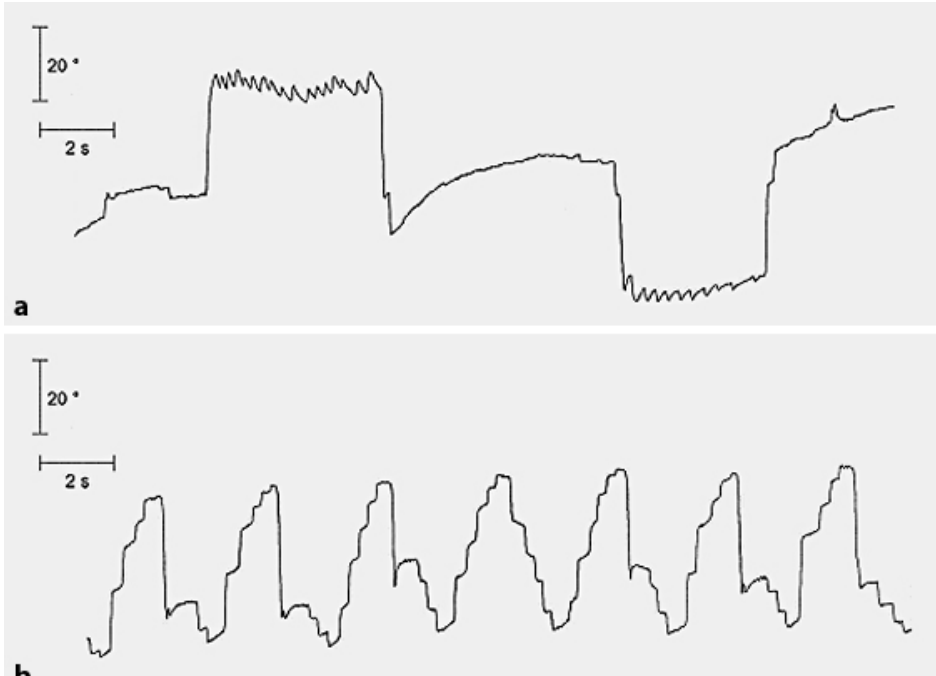

b

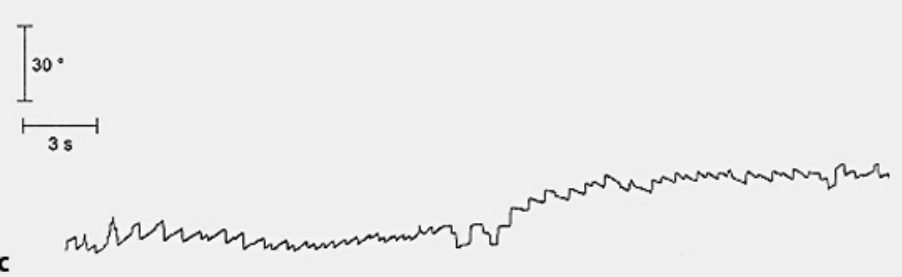

Fig. 1. Oculomotor abnormalities as evident from electronystagmography. a Gaze-evoked nystagmus in fast right and left horizontal saccades. b Abolition of pursuit eye movement by saccades. c Normal optokinetic nystagmus in both horizontal directions. 


\begin{tabular}{c|l|l|l} 
Case Reports in & $\begin{array}{l}\text { Case Rep Neurol 2011;3:54-61 } \\
\text { DOl: 10.1159/000324927 }\end{array}$ & $\begin{array}{l}\text { Published online: } \\
\text { February 21, 2011 }\end{array}$ & $\begin{array}{l}\text { O 2011 S. Karger AG, Basel } \\
\text { ISSN 1662-680X } \\
\text { www.karger.com/crn }\end{array}$ \\
\hline
\end{tabular}
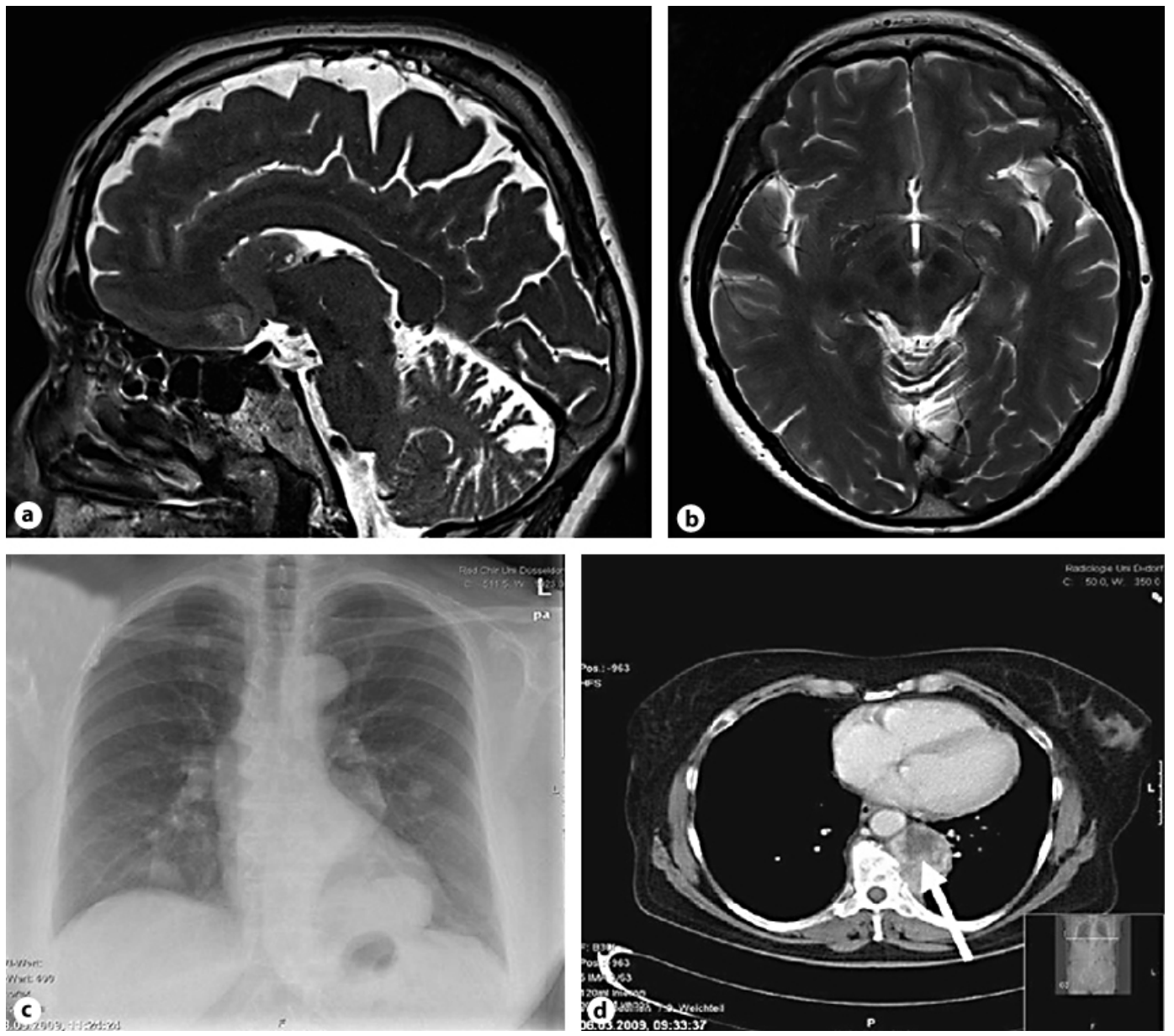

Fig. 2. MRI scan of the brain. Slight atrophy of the upper cerebellar vermis and the superior semilunar lobes in a sagittal (a) and axial projection (b). Chest X-ray (c) and CT scan (d): several bilateral pulmonary metastases and a subpleural metastasis posterior of the left ventricle (arrow). 


\begin{tabular}{l|l|l|l} 
Case Reports in & $\begin{array}{l}\text { Case Rep Neurol 2011;3:54-61 } \\
\text { DOI: } 10.1159 / 000324927\end{array}$ & $\begin{array}{l}\text { Published online: } \\
\text { February 21, 2011 }\end{array}$ & $\begin{array}{l}\text { ○ 2011 S. Karger AG, Basel } \\
\text { ISSN 1662-680X } \\
\text { www.karger.com/crn }\end{array}$ \\
\hline
\end{tabular}
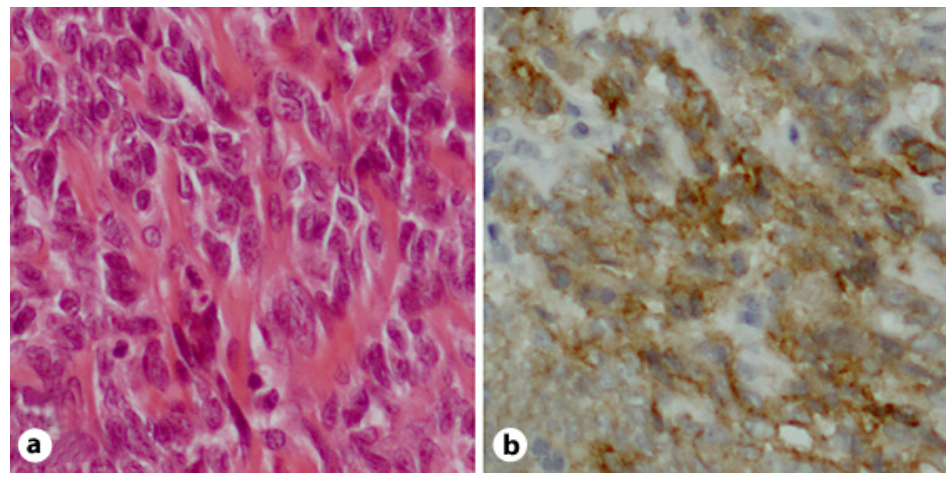

Fig. 3. HE morphology and immunohistochemistry of a lung metastasis of the low-grade ESS. a Morphological assessment revealed a tumor composed of round to oval cells with slightly pleomorphic nuclei and small nucleoli as well as hyaline intercellular substance between the tumor cells in the HE stain ( $\times 200$ magnification). b Immunohistochemical analysis revealed CD10 positivity of the tumor cells $(\times 200$ magnification).

\section{References}

1 Santillan A, Bristow RE: Paraneoplastic cerebellar degeneration in a woman with ovarian cancer. Nat Clin Pract Oncol 2006;3:108-112.

-2 Posner JB, Dalmau J: Clinical enigmas of paraneoplastic neurologic disorders. Clin Neurol Neurosurg 1995;97:61-70.

-3 Furneaux HM, Rosenblum MK, Dalmau J, Wong E, Woodruff P, Graus F, Posner JB: Selective expression of Purkinje-cell antigens in tumor tissue from patients with paraneoplastic cerebellar degeneration. N Engl J Med 1990;322:1844-1851.

-4 Graus F, Delattre JY, Antoine JC, Dalmau J, Giometto B, Grisold W, Honnorat J, Smitt PS, Vedeler C, Verschuuren JJ, Vincent A, Voltz R: Recommended diagnostic criteria for paraneoplastic neurological syndromes. J Neurol Neurosurg Psychiatry 2004;75:1135-1140.

5 Amant F, Coosemans A, Debiec-Rychter M, Timmerman D, Vergote I: Clinical management of uterine sarcomas. Lancet Oncol 2009;10:1188-1198.

6 Chang KL, Crabtree GS, Lim-Tan SK, Kempson RL, Hendrickson MR: Primary uterine endometrial stromal neoplasms. A clinicopathologic study of 117 cases. Am J Surg Pathol 1990;14:415-438.

7 Clement PB, Scully RE: Uterine tumors resembling ovarian sex-cord tumors. A clinicopathologic analysis of fourteen cases. Am J Clin Pathol 1976;66:512-525.

8 Irving JA, Carinelli S, Prat J: Uterine tumors resembling ovarian sex cord tumors are polyphenotypic neoplasms with true sex cord differentiation. Mod Pathol 2006;19:17-24.

-9 Piver MS, Rutledge FN, Copeland L, Webster K, Blumenson L, Suh O: Uterine endolymphatic stromal myosis: a collaborative study. Obstet Gynecol 1984;64:173-178.

10 Bodner K, Bodner-Adler B, Obermair A, Windbichler G, Petru E, Mayerhofer S, Czerwenka K, Leodolter S, Kainz C, Mayerhofer K: Prognostic parameters in endometrial stromal sarcoma: a clinicopathologic study in 31 patients. Gynecol Oncol 2001;81:160-165.

11 Chan JK, Kawar NM, Shin JY, Osann K, Chen LM, Powell CB, Kapp DS: Endometrial stromal sarcoma: a population-based analysis. Br J Cancer 2008;99:1210-1215. 
12 Amant F, De KA, Van CB, Leunen K, Neven P, Berteloot P, Vergote I, Van HS, Moerman P: Clinical study investigating the role of lymphadenectomy, surgical castration and adjuvant hormonal treatment in endometrial stromal sarcoma. Br J Cancer 2007;97:1194-1199.

13 Chu MC, Mor G, Lim C, Zheng W, Parkash V, Schwartz PE: Low-grade endometrial stromal sarcoma: hormonal aspects. Gynecol Oncol 2003;90:170-176.

14 Reich O, Regauer S: Hormonal therapy of endometrial stromal sarcoma. Curr Opin Oncol 2007;19:347-352.

- 15 Vedeler CA, Antoine JC, Giometto B, Graus F, Grisold W, Hart IK, Honnorat J, Sillevis Smitt PA, Verschuuren JJ, Voltz R: Management of paraneoplastic neurological syndromes: report of an EFNS Task Force. Eur J Neurol 2006;13:682-690. 